\title{
The Kinetics of Donor Cell mtDNA in Embryonic and Somatic Donor Cell-Derived Bovine Embryos
}

\author{
CHRISTINA RAMIRES FERREIRA, ${ }^{1,2}$ FLÁVIO VIEIRA MEIRELLES, ${ }^{2}$ WALT YAMAZAKI, ${ }^{1}$ \\ MARCOS ROBERTO CHIARATTI, ${ }^{2}$ SIMONE CRISTINA MÉO, ${ }^{3}$ FELIPE PERECIN, ${ }^{1}$ \\ LAWRENCE CHARLES SMITH, ${ }^{4}$ and JOAQUIM MANSANO GARCIA ${ }^{1}$
}

\begin{abstract}
The mechanisms controlling the outcome of donor cell-derived mitochondrial DNA (mtDNA) in cloned animals remain largely unknown. This research was designed to investigate the kinetics of somatic and embryonic mtDNA in reconstructed bovine embryos during preimplantation development, as well as in cloned animals. The experiment involved two different procedures of embryo reconstruction and their evaluation at five distinct phases of embryo development to measure the proportion of donor cell mtDNA (Bos indicus), as well as the segregation of this mtDNA during cleavage. The ratio of donor cell (B. indicus) to host oocyte (B. taurus) mtDNA (heteroplasmy) from blastomere- (NT-B) and fibroblast- (NT-F) reconstructed embryos was estimated using an allele-specific PCR with fluorochrome-stained specific primers in each sampled blastomere, in whole blastocysts, and in the tissues of a fibroblast-derived newborn clone. NT-B zygotes and blastocysts show similar levels of heteroplasmy $(\mathbf{1 1 . 0} \%$ and $\mathbf{1 4 . 0} \%$, respectively), despite a significant decrease at the 9-16 cell stage $(5.8 \% ; p<0.05)$. Heteroplasmy levels in NT-F reconstructed zygotes, however, increased from an initial low level $(4.7 \%)$, to $12.9 \%(p<0.05)$ at the $9-16$ cell stage. The NT-F blastocysts contained low levels of heteroplasmy $(2.2 \%)$ and no somatic-derived mtDNA was detected in the gametes or the tissues of the newborn calf cloned. These results suggest that, in contrast to the mtDNA of blastomeres, that of somatic cells either undergoes replication or escapes degradation during cleavage, although it is degraded later after the blastocyst stage or lost during somatic development, as revealed by the lack of donor cell mtDNA at birth.
\end{abstract}

\section{INTRODUCTION}

$\mathbf{Z}$ ebu (Bos indicus) and European bReeds of cattle (B. taurus) differ primarily in relation to the presence or absence of a hump, respectively (MacHugh et al., 1997). Differences in mitochondrial DNA (mtDNA) sequences suggest that these Asian and European species diverged between 200,000 and 1 million years ago (Loftus et al., 1994), but have maintained complete interfertility; moreover, it is likely that mtDNA polymorphism has played a significant role in the natural selection process involved in the adaptation of different breeds of cattle to regional environmental conditions (Schutz et al., 1994).

\footnotetext{
${ }^{1}$ Departamento de Medicina Veterinária Preventiva e Reprodução Animal, FCAV-UNESP Jaboticabal-SP, Brazil.

${ }^{2}$ Departamento de Ciências Básicas, FZEA-USP, Pirassununga-SP, Brazil.

${ }^{3}$ Instituto de Zootecnia, Nova Odessa-SP, Brazil.

${ }^{4}$ CRRA, Université de Montréal, Saint-Hyacinthe-QC, Canada.
} 
Mammalian mtDNA is a closed circular molecule with approximately $16 \mathrm{~kb}$ which is present in high ploidy inside the mitochondria. There is a close relationship between the quantity of mtDNA and the production of energy in the cell (Williams, 1986), because the mtDNA is responsible for synthesizing some of the enzymatic complexes involved in oxidative phosphorylation (OXPHOS; reviewed by Chen and Butow, 2005). The nucleus synthesizes all the enzymes and factors required for mtDNA replication, and these are imported by the mitochondria; in this way, expression of mitochondrial and nuclear-encoded subunits of the respiratory chain complex is coordinated by specific transcription factors, such as the PPAR Gamma Coactivator (PGC)-1 (Puigserver et al., 1998) and PGC-1-related coactivator (Andersson and Scarpulla, 2001). These transcription factors, in turn, interact with the nucler respiration factor 1 (NRF-1). The NRF-1 then activates transcription of several mitochondrial nuclear-encoded proteins (Scarpulla, 1997). The mitochondrial transcription factor (mtTFA), activated by NRF-1, is necessary for mtDNA replication (Chang and Clayton, 1984). Also, a specific DNA polymerase, polymerase, exists in the mitochondria (reviewed by Clayton, 2000).

The mtDNA is commonly present in an organism as a single haplotype (homoplasmy). This is the result of non-Mendelian inheritance, which leads to the transmission of the mtDNA from the oocyte from one generation to succeeding generations (Birky, 1994; Giles et al., 1980; Hutchinson et al., 1974). This seems to occur because sperm mitochondria are actively destroyed shortly after fertilization (Sutovsky et al. 1999).

Cloning alters the inheritance of mtDNA, because it introduces a situation of heteroplasmy in the cloned organism. The condition of artificial heteroplasmy has been studied in murine models of mtDNA, and its evolution was investigated in germ cells, during tissue differentiation, as well as in mtDNA inheritance in succeeding generations (Jenuth et al., 1996; Meirelles and Smith, 1997; Smith and Alcivar, 1993). The selection of specific mtDNA haplotypes was reported and suggested to be related to nuclear factors involved in $\mathrm{mtDNA}$ maintenance and turnover (Battersby and Shoudbridge, 2001; Takeda, et al., 2000) or to preferential access to nuclear transcription factors after karyoplast transfer (Meirelles and Smith, 1998).

Studies of mitochondrial composition in cloned mammals (Evans et al., 1999; Plante et al., 1992;
Steinborn et al., 2000), however, have generally concluded that all or most of the mtDNA present was derived from the recipient oocyte, which has lead to a general consensus that animals developing from donors with identical nuclei often represent "genomic copies" rather than true clones (Campbell, 1999).

In the bovine model produced by nuclear transfer, donor cell-derived mitochondria are reported to undergo a stringent genetic drift during development, leading, in most cases, to a reduction or complete elimination of donor cell mtDNA (Meirelles et al., 2001; Plante et al., 1992; Steinborn et al., 1998a, 1998b). When blastomere-derived clones are involved, however, larger amounts of donor-derived mtDNA can be incorporated, due to the quantity of donor cell cytoplasm present during reconstruction (Hiendleder et al., 1999; Steinborn et al., 2002; Takeda et al., 1999). The divergent results may, however, be related to differences in nuclear transfer protocols, nuclear background of recipient oocytes, nuclear-cytoplasmic compatibility after reconstruction, or the specific mtDNA haplotype studied (Hiendleder et al., 2003).

The present paper was designed to compare the segregation of the mtDNA of embryos reconstructed from $B$. taurus recipient oocytes and $B$. indicus nuclei, either from adult fibroblasts or embryonic cells (from 16-cell stage embryos). Preimplantation development, as well as the tissues and oocytes of the calf born from somatic cell nuclear transfer (SCNT), were analyzed.

\section{MATERIALS AND METHODS}

\section{Animals}

The Institutional Animal Care and Use Committee at the Jaboticabal Campus of the São Paulo State University (UNESP) approved the procedures for the use of animals for this investigation (protocol number 016177-06). The animals were maintained in a pasture, with free access to water and mineral supplements.

\section{Chemicals and incubator conditions}

Unless mentioned elsewhere, chemicals and growth media were purchased from Sigma (St. Louis, MO). Incubator conditions for oocytes and embryos, as well as fibroblast cultures, were maintained at $38.5^{\circ} \mathrm{C}$ in air with $5 \% \mathrm{CO}_{2}$ and maximum humidity for all experiments. 


\section{Experimental procedures}

The first procedure involved the reconstruction of embryos from fibroblast nuclei (NT-F). The second involved that of embryos reconstructed from embryonic donor nuclei (NT-B). After reconstruction, the embryos in initial developmental stages (until fourth cell cycle) were disaggregated, and individual blastomeres were collected for the assessment of the proportion of the two possible types of mtDNA. Five stages of embryo development were investigated: stages with two cells (G1), 4 cells (G2), 5-8 cells (G3), and 9-16 cells (G4). The blastocyst stage was also studied, but the entire blastocyst was collected and analyzed as a whole.

Samples were collected within fixed intervals of time after embryo reconstruction had occurred; the establishment of a fixed interval was designed to avoid analysis of embryos with delayed or arrested development. Blastomeres from embryos with two cells were collected between 24 and 40 $\mathrm{h}$ postreconstruction; embryos with at least four cells were obtained by $51 \mathrm{~h}$, while five- to eightcell embryos were obtained by $63 \mathrm{~h}$, and embryos with 9 to 16 cells were harvested until $94 \mathrm{~h}$. Blastocysts were collected at $168 \mathrm{~h}$ postreconstruction.

\section{Source of recipient cytoplasts}

Oocytes harboring B. taurus mtDNA were obtained postmortem by follicular aspiration from the ovaries of Nellore unregistered cows (with $B$. indicus nuclear DNA and $B$. taurus mtDNA) slaughtered at a local slaughterhouse. The ovaries were transported in saline solution $0.9 \%$ at $25-30^{\circ} \mathrm{C}$ to the laboratory. Follicles with diameters between 3 and $8 \mathrm{~mm}$ were aspirated using an 18-gauge needle attached to a $20-\mathrm{mL}$ syringe and cumulus oocyte complexes (COCs) with at least three layers of cumulus cells and homogeneous cytoplasm were washed in HEPESbuffered tissue culture medium-199 (TCM-199; GIBCO BRL ${ }^{\circledR}$, Grand Island, NY) supplemented with $10 \%$ fetal calf serum (FCS) heat-inactivated at $55^{\circ} \mathrm{C}$ for $30 \mathrm{~min}$, as well as $16 \mu \mathrm{g} / \mathrm{mL}$ sodium pyruvate and $75 \mu \mathrm{g} / \mathrm{mL}$ kanamycin. Groups of 20-25 COCs were placed in $100 \mu \mathrm{L}$ of bicarbonate-buffered TCM-199 supplemented with 10\% FCS, $16 \mu \mathrm{g} / \mathrm{mL}$ sodium pyruvate, $75 \mu \mathrm{g} / \mathrm{mL}$ kanamycin, $0.5 \mu \mathrm{g} / \mathrm{mL}$ FSH (Folltropin ${ }^{\mathrm{TM}}$; Vetepharm Inc., London, Canada), $5 \mu \mathrm{g} / \mathrm{mL}$ LH (Lutropin- $V^{\mathrm{TM}}$, Vetepharm Inc., London, Canada), and $1 \mu \mathrm{g} / \mathrm{mL}$ estradiol under mineral oil (Dow Corning CO., Midland, MI) for in vitro maturation (IVM).

\section{Sources of donor cells}

Donor cells to supply the nuclei for the clones resulted from two distinct procedures. In the first procedure involving the transfer of fibroblast nuclei (NT-F), fibroblasts were derived from the skin biopsy of a 16-year-old Nellore cow with a pedigree of Pure Imported Origin (PIO) breed; and with $B$. indicus mtDNA (Meirelles et al., 1999). The skin biopsy was used to establish a primary cell line in Dulbecco's modified Eagle's medium (DMEM; Gibco BRL $^{\circledR}$ ) supplemented with $40 \%$ FCS and 75 $\mu \mathrm{g} / \mathrm{mL}$ kanamycin; the resultant cells were then cultured in DMEM supplemented with $10 \%$ FCS and $75 \mu \mathrm{g} / \mathrm{mL}$ kanamycin. Cell passage was performed by treating confluent cells with $0.25 \%$ trypsin and $0.1 \%$ EDTA. Cell lines cultured for three to nine passages were then serum starved $(0.5 \%$ FCS) for 5-12 days before use for nuclear transfer.

The second procedure involved the transfer of 16-cell embryo-derived blastomere nuclei (NT-B). Oocytes carrying $B$. indicus mtDNA were obtained by ovum pickup (OPU; Pieterse et al., 1988) from PIO Nellore cows with a confirmed B. indicus mtDNA haplotype (Meirelles et al., 1999). COCs recovered by OPU were transported in PBS at $25-30^{\circ} \mathrm{C}$ to the laboratory and submitted to IVM for $24 \mathrm{~h}$. OPU-collected oocytes were then fertilized in TALP-IVF medium supplemented with $0.6 \% \mathrm{BSA}, 10 \mu \mathrm{g} / \mathrm{mL}$ heparin, $18 \mu \mathrm{M}$ penicillamine, $10 \mu \mathrm{M}$ hypotaurine and $1.8 \mu \mathrm{M}$ epinephrine. Motile thawed spermatozoa from a $B$. indicus bull were separated by density gradient in $45 \%$ and $90 \%$ Percoll. Final sperm concentration used was $2.5 \times 10^{6}$ live spermatozoa $/ \mathrm{mL}$. Oocytes and sperm were coincubated for $24 \mathrm{~h}$ for in vitro fertilization (IVF); after this period, presumptive zygotes were washed in TALP-IVF medium and cultured in vitro (IVC) in $100 \mu \mathrm{L}$ drops of modified synthetic oviduct fluid medium (SOF; Vajta et al., 1999) supplemented with $2.5 \%$ FCS and $0.5 \%$ BSA under mineral oil. Embryos were cultured to the 16-cell stage; the zona pellucida was then removed in $0.5 \%$ pronase, and the blastomeres dissociated in $\mathrm{Ca}^{++}$- and $\mathrm{Mg}^{++}$-free PBS supplemented with $0.3 \%$ polyvinyl alcohol (PVA) for use as nucleus donor cells. 


\section{Microsurgery and parthenogenetic activation}

Oocyte reconstruction was performed using standard procedures under an inverted microscope (Olympus IX-70, Tokyo, Japan) equipped with a heating plate set at $38.5^{\circ} \mathrm{C}$, micromanipulators and microinjectors (Narishige, Tokyo, Japan). Microsurgery was carried out in a $300 \mu \mathrm{L}$ drop of HEPES-buffered SOF (HSOF; Wells et al., 1999) supplemented with 10\% FCS and 7.5 $\mu \mathrm{g} / \mathrm{mL}$ cytochalasin $\mathrm{B}(\mathrm{CB})$ under mineral oil in a plastic Petri dish.

Briefly, after $21 \mathrm{~h}$ of IVM, oocytes to be used as recipient cytoplasts for the NT-F procedure had their cumulus cells removed by gentle pipetting in $0.2 \%$ hyaluronidase. Oocytes presenting the first polar body (1st $\mathrm{PB}$ ) were incubated in HSOF supplemented with $10 \mu \mathrm{g} / \mathrm{mL}$ Hoechst 33342 and $7.5 \mu \mathrm{g} / \mathrm{mL} \mathrm{CB}$ for $15 \mathrm{~min}$. Using a 25 $\mu \mathrm{m}$ (external diameter) glass micropipette, metaphase II chromosomes and the 1st PB were removed and exposed to ultraviolet light to confirm oocyte enucleation. A single $B$. indicus fibroblast was then injected into the perivitelline space of each enucleated oocyte containing $B$. taurus $m t D N A$. The resulting couplet was placed in an electrofusion solution ( $0.28 \mathrm{M}$ mannitol, $0.05 \mathrm{mM}$ $\mathrm{CaCl}_{2}, 0.1 \mathrm{mM} \mathrm{MgSO}_{4}, 0.5 \mathrm{mM}$ HEPES acid, and $0.05 \%$ BSA; Wells et al., 1999) and exposed to two electrical pulses of $2.25 \mathrm{kV} / \mathrm{cm}$ for $20 \mu \mathrm{sec}$ from an electrofusor (ECM-2001 BTX, San Diego, CA). Reconstructed oocytes were chemically activated at $30 \mathrm{~h}$ post-IVM through incubation in HSOF supplemented with $10 \%$ FCS and $5 \mu \mathrm{M}$ ionomycin for $5 \mathrm{~min}$, followed by incubation for $6 \mathrm{~h}$ in SOF supplemented with $20 \mathrm{mM}$ strontium $\left(\mathrm{SrCl}_{2} \cdot 6 \mathrm{H}_{2} \mathrm{O}\right.$; Riedel-de-Haën; VETEC, Rio de Janeiro, RJ, Brazil) and $10 \mu \mathrm{g} / \mathrm{mL}$ CB.

For the NT-B procedure, oocytes were enucleated at the telophase II stage (Bordignon and Smith, 1998). The technique involved parthenogenetic activation at $30 \mathrm{~h}$ post-IVM in $5 \mu \mathrm{M}$ ionomycin for $5 \mathrm{~min}$. At $32 \mathrm{~h}$ postmaturation, those oocytes presenting the second polar body (2nd $\mathrm{PB})$ were incubated in HSOF with $10 \mu \mathrm{g} / \mathrm{mL}$ Hoechst 33342 and $7.5 \mu \mathrm{g} / \mathrm{mL}$ CB for $15 \mathrm{~min}$. Using a $25 \mu \mathrm{m}$ (external diameter) glass micropipette, the 2nd PB and surrounding cytoplasm were removed. Enucleated oocytes were then washed in HEPES-buffered TCM-199 and incubated in HSOF supplemented with 10\% FCS until microsurgery, at which time they were incubated for $30 \mathrm{~min}$ in HSOF medium with 7.5 $\mu \mathrm{g} / \mathrm{mL}$ CB. For reconstruction, a single blastomere originating from a 16-cell stage embryo previously incubated for $30 \mathrm{~min}$ in HSOF medium with $7.5 \mu \mathrm{g} / \mathrm{mL} \mathrm{CB}$ was injected into the perivitelline space of the enucleated oocyte containing B. taurus mtDNA. Electrofusion was performed using two electrical pulses of $1.25 \mathrm{kV} / \mathrm{cm}$ for $30 \mu$ sec each.

\section{In vitro culture of embryos}

Embryos successfully reconstructed using the NT-F and NT-B procedures were cocultured with granulosa cells in $100 \mu \mathrm{L}$ drops of SOF supplemented with $2.5 \%$ FCS and $0.6 \%$ BSA under mineral oil.

\section{Embryo transfer of NT-F blastocysts to recipient cows and cloned calf sample collection}

NT-F blastocysts were transferred nonsurgically into the uterus of previously synchronized recipient cows (one or two embryos per cow). The animals were evaluated by ultrasound examination or palpated per rectum on days 50, 60, and 90 of gestation; the pregnancies were then allowed to develop to term.

When the calf was born, its blood and skin, as well as fetal membrane samples (allantois, umbilical cord, cotyledon, and uracus) were collected, while primordial follicles and immature oocytes were obtained after its death after 1 month.

\section{Embryo sample collection and mtDNA segregation analysis}

Sample embryos were selected on the basis of the number of blastomeres present (as explained elsewhere), with the selection starting $24 \mathrm{~h}$ postactivation, after cleavage had occurred. The zona pellucida was removed through incubation in PBS with $0.5 \%$ pronase, and the blastomeres were individualized in $\mathrm{Ca}^{++}$- and $\mathrm{Mg}^{++}$-free PBS supplemented with $0.3 \%$ PVA using a fine-bore pipette. The presence of the nucleus was confirmed by staining the blastomeres with 10 $\mu \mathrm{g} / \mathrm{mL}$ Hoechst 33342 during $15 \mathrm{~min}$, followed by visualization under ultraviolet light. The separated blastomeres, as well as entire blastocysts were washed in PCR buffer and individually placed in labeled $0.2 \mathrm{~mL}$ PCR microtubes containing $5 \mu \mathrm{L}$ of ultrapure water and stored at $-80^{\circ} \mathrm{C}$ until proteinase $\mathrm{K}$ digestion $(1 \mathrm{mg} / \mathrm{mL}$; $37^{\circ} \mathrm{C}$ for $1 \mathrm{~h}$ and $94^{\circ} \mathrm{C}$ for $10 \mathrm{~min}$ ). Genomic DNA from tissue samples of the cloned calf was ex- 
tracted according to standard protocols (Sambrook and Russel, 2001).

The content of B. indicus and B. taurus mtDNA in each sample was analyzed by densitometry after electrophoresis of amplified PCR fragments. The PCR reaction involved the use of three primers to amplify a 365-bp fragment from the 16S (rRNA) gene of both B. taurus and B. indicus mtDNA. Specific forward primers were stained with fluorochromes, either 6-FAM (5'-FAMCCAATGATAACATCTCAACTG-3') or TAMRA (5'-TAMRA-CCAATGACAGCATCTCAATCA$\left.3^{\prime}\right)$, for B. taurus and B. indicus mtDNA annealing, respectively. The nonstained unspecific reverse primer, BOS MTDNA 3339R (5'-GAGCTATGATGGGTGCTAGG-3') annealed unspecifically with both $B$. indicus and B. taurus mtDNA.

The PCR reaction mixture consisted of $10 \mathrm{pmol}$ of each of the above-mentioned primers; $20 \mathrm{mM}$ Tris- $\mathrm{HCl}$ (pH 8.4); $50 \mathrm{mM} \mathrm{KCl} ; 5 \mathrm{mM} \mathrm{MgCl}_{2} ; 600$ $\mu \mathrm{M}$ each of dGTP, dATP, dTTP, and dCTP (dNTP; Gibco BRL ${ }^{\circledR}$, Grand Island, NY) and 1.25 U Taq polymerase (Gibco BRL ${ }^{\circledR}$ ) for a final volume of $30 \mu \mathrm{L}$. PCR was performed using $36 \mathrm{cy}-$ cles, each consisting of denaturation for $45 \mathrm{sec}$ at $94^{\circ} \mathrm{C}$, annealing for $55 \mathrm{sec}$ at $58^{\circ} \mathrm{C}$, and extension for $120 \mathrm{sec}$ at $72^{\circ} \mathrm{C}$ in a Genius thermocycler (Techne Limited, Cambridge, United Kingdom). The amplified fragments were loaded on $1.2 \%$ agarose gels for electrophoresis. Gels were visualized in a FLA-3000G Fujifilm ${ }^{\circledR}$ scanner (Tokyo, Japan) using 473-520 nm wavelengths for detecting the fluorochrome 6-FAM marker and 532-580 $\mathrm{nm}$ for detecting the fluorochrome TAMRA marker. After analysis of the TAMRA and 6-FAM markers using densitometry values (Image Gauge v.3.12 software; Fuji Photo Film, Tokyo, Japan), the proportion of $B$. indicus mtDNA was determined by dividing the integrated density of the specific band of the TAMRA marker by that of the 6-FAM marker.

Because intensity of fluorescence was different for the two fluorochromes, compensation by the use of linear regressions was necessary. These regressions were constructed on the basis of oocyte mixtures with $B$. indicus $/ B$. taurus mtDNA ratios ranging from $1 / 1$ to $1 / 100$ (Fig. 1), with the sensitivity of the test estimated to be $1 \%$.

Samples containing more than 20\% heteroplasmy were thus subjected to mathematical correction using the linear regression shown in Figure $1 \mathrm{~A}$, while those containing less than $20 \%$ involved the use of the linear regression shown in Figure 1B. Mathematically corrected data, ex-
A

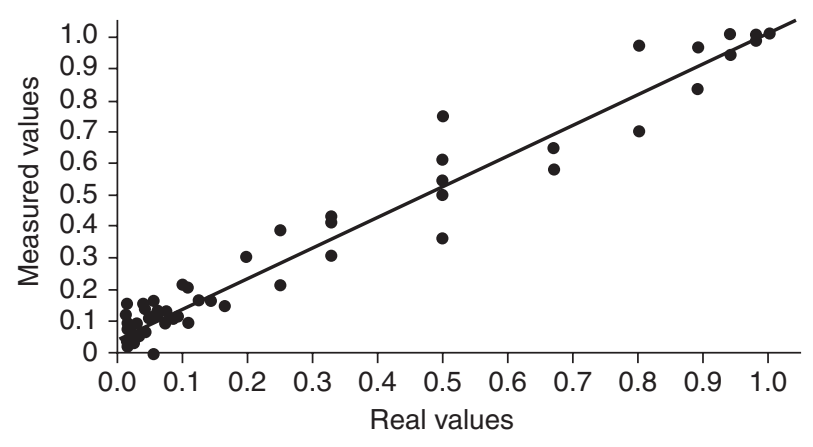

B

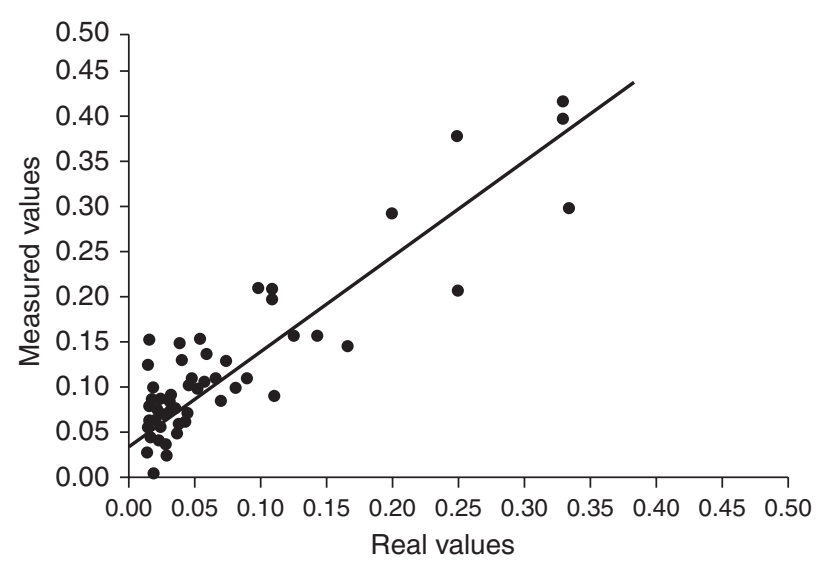

C
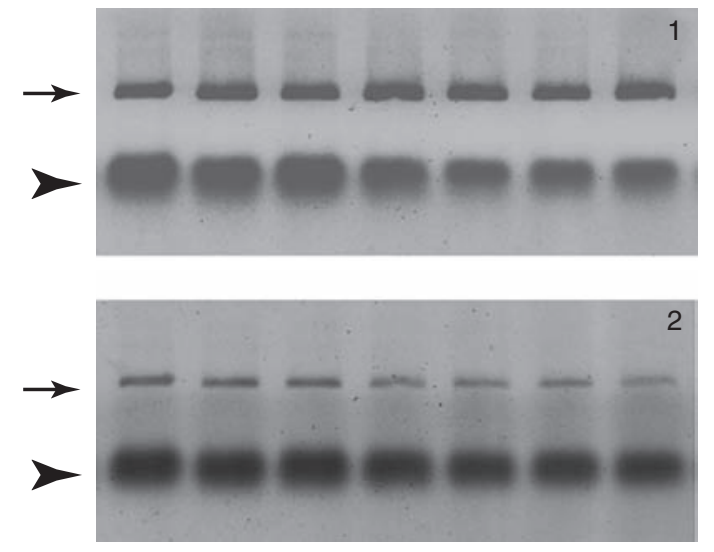

FIG. 1. Linear regressions obtained from amplification of samples containing $B$. taurus and $B$. indicus mtDNA oocyte mixtures. The regression in (A) was used to correct samples showing more than $20 \%$ of heteroplasmy $\left(R^{2}=0.97\right)$. The regression in (B) was established using up to $50 \%$ heteroplasmy, and was used to correct measured sample values below $20 \%$ heteroplasmy $\left(R^{2}=0.82\right)$. Images in (C) show amplified mtDNA fragments of 365 $\mathrm{bp}$ (arrows) from oocyte mixtures containing from 33\% (extreme left) to $11 \%$ (extreme right) B. indicus mtDNA loaded onto a $1.2 \%$ agarose gel. Image $\mathrm{C} 1$ was obtained from scanning the gel with $473-520 \mathrm{~nm}$ wavelengths to detect the fluorochrome 6-FAM (B. taurus mtDNA), and that of $C 2$ was scanned with $532-580 \mathrm{~nm}$ to detect the fluorochrome TAMRA (B. indicus mtDNA). Fluorochromestained primers remaining from the PCR (arrowheads). 
pressed as a percentage, were transformed $(1 / \log )$ in order to obtain a normal distribution and submitted to an analysis of variance and a Student $t$ test at a $5 \%$ level of significance using JMP software (SAS Institute, Cary, NC).

Outlier samples $( \pm 3 \mathrm{SD})$ were excluded from the calculation of group means and statistical analyses. In order to evaluate mtDNA segregation in the embryos during successive cleavages, the coefficient of variation (CV) was calculated.

Additional tests were made to increase the sensitivity to the presence of $B$. indicus mtDNA by eliminating the 6-FAM primer and using only the TAMRA primer specific for this haplotype, and the nonspecific primer. Another PCR reaction, containing only the the 6-FAM primer and the nonspecific primer, was made in parallel to assure a specific amplification. For the analysis of the oocytes, the lysate containing the mtDNA was divided between the two PCR reactions (Fig. 4). This adaptation provided a qualitative evaluation of the presence of $B$. indicus mtDNA in the tissues and oocytes of the cloned calf. As B. indicus primers were $100 \%$ specific at conditions described above, the sensitivity of the qualitative test (using two primers) was up to one molecule.

\section{RESULTS}

Experimental groups

A total of 215 individual blastomeres, representing 76 embryos (NT-B procedure, $n=40$; NT-
F procedure, $n=36$ ), were recovered at various stages of development, as well as 22 whole blastocysts (NT-B procedure, $n=12$; NT-F procedure, $n=10)$, and had the percentage of $B$. indicus mtDNA for successful trials analyzed (Table 1).

\section{Heteroplasmy kinetics during preimplantation development of NT-B and NT-F embryos}

The proportion of $B$. indicus $\mathrm{mtDNA}$ in the blastomeres of each embryo is show for the NT-B (Fig. 2A) and NT-F (Fig. 2B) procedures. Outlier embryos, that is, with unexpectedly high $B$. indicus mtDNA content $(45.2 \%$ to $83.5 \%$ ) are indicated in Figure $2 \mathrm{~A}$ as encircled dots. The results show that the distribution of heteroplasmy is similar for all developmental phases of embryos resulting from the NT-B procedure, whereas for those from the NT-F procedure, variation in heteroplasmic distribution was found for the third (G3) and fourth stages (G4).

Although the average heteroplasmy was similar for the initial and final stages of development for embryos obtained from the two procedures, heteroplasmy kinetics was different for the two sets of embryos (Fig. 2C and D). In the case of NT-B embryos, average heteroplasmy decreased at the fourth stage, but rose to initial levels at the blastocyst stage. In the case of the NT-F procedure, the average heteroplasmy, which was initially relatively low, increased at the fourth stage, but decreased at the blastocyst stage.

Table 1. Mean Percentage and SE of B. indicus mtDNA in Reconstructed Bovine Embryos from Somatic (NTF) and Embryonic (NT-B) Donor Cells During the Four Initial Stages of Development to the Blastocyst Stage

\begin{tabular}{|c|c|c|c|c|}
\hline Procedure & $\begin{array}{c}\text { Developmental } \\
\text { stage }^{\mathrm{a}}\end{array}$ & $\begin{array}{c}\text { No. of } \\
\text { blastomeres } \\
\text { (outliers) }^{\mathrm{b}}\end{array}$ & $\begin{array}{l}\text { No. of embryos } \\
\text { (outliers) }^{\mathrm{b}}\end{array}$ & $\begin{array}{l}\text { B. indicus } \\
m t D N A \\
\%( \pm S E)\end{array}$ \\
\hline \multirow[t]{5}{*}{ NT-B } & G1 & $30(4)$ & $16(2)$ & $11.0^{\text {de }}(1.71)$ \\
\hline & $\mathrm{G} 2$ & $25(4)$ & $8(1)$ & $14.0^{\mathrm{d}}(2.47)$ \\
\hline & G3 & $36(0)$ & $9(0)$ & $8.8^{\text {de }}(1.83)$ \\
\hline & G4 & $37(0)$ & $7(0)$ & $5.8^{\mathrm{e}}(1.49)$ \\
\hline & Blt & - & $12(2)$ & $13.9^{a}(1.46)$ \\
\hline \multirow[t]{6}{*}{ NT-F } & G1 & $22(0)$ & $12(0)$ & $4.7^{\mathrm{ef}}(0.40)$ \\
\hline & $\mathrm{G} 2$ & $9(0)$ & $4(0)$ & $4.9^{\text {def }}(4.00)$ \\
\hline & G3 & $30(0)$ & $13(0)$ & $9.0^{\text {de }}(2.97)$ \\
\hline & G4 & $26(0)$ & $7(0)$ & $12.9^{\mathrm{d}}(3.88)$ \\
\hline & Blt & - & $10(0)$ & $2.2^{\mathrm{f}}(0.39)$ \\
\hline & Total & $215^{c}(8)$ & $98(5)$ & \\
\hline
\end{tabular}

aThe stages correspond to the two-cell stage (G1), four-cell stage (G2), five to eight-cell stage (G3), and 9-16 cell stage (G4), as well as the blastocyst (Blt) stage.

${ }^{\mathrm{b}}$ Outliers $=$ samples harboring a percentage of $B$. indicus mtDNA outside the interval \pm 3 SD.

cNumber of blastomeres corresponding to the 76 embryos. Blastocysts (total of 22) were not included.

defValues with different superscripts within columns and for the same procedure are significantly different $(p<0.05)$. The analysis did not include embryos with a high percentage of $B$. indicus mtDNA. 


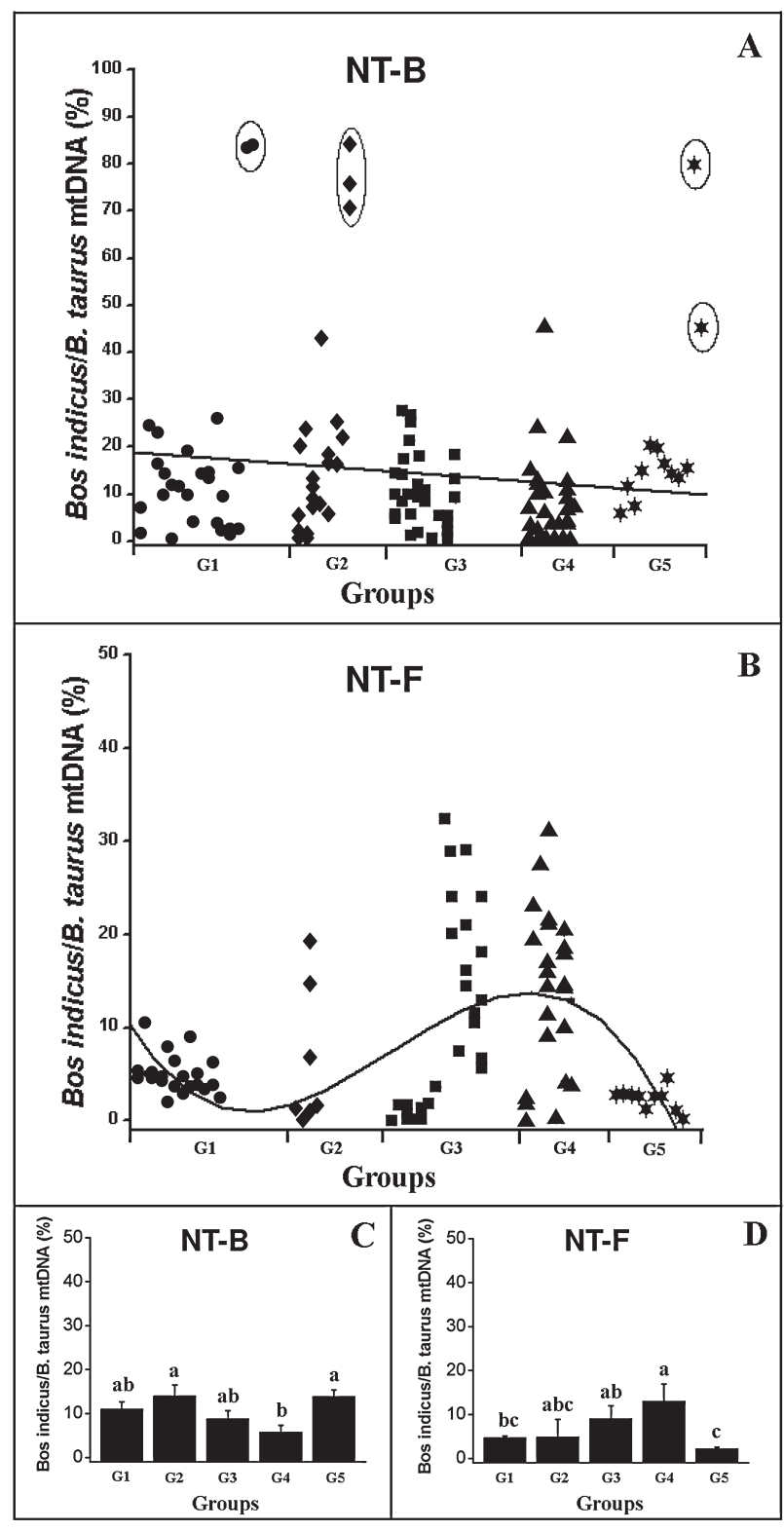

FIG. 2. Distribution of blastomeres in the five stages of development from NT-B (A) and NT-F (B) procedures (horizontal axis) showing heteroplasmy level (vertical axis), and tendency lines. Values on the same vertical line represent blastomeres from the same embryo. Blastocysts are represented by a single point, because they were analyzed as whole embryos. Mean embryo heteroplasmy for NT-B and NT-F procedures are depicted in (C) and (D), respectively. Different letters indicate statistical differences between developmental stages involving the same procedure $(p<0.05)$.

The CVs of the embryos are directly related to segregation patterns, and these were used for the comparison of the embryos at different developmental stages for the two procedures (Fig. 3). The $\mathrm{CV}$ values show that the kinetics of the two procedures lead to totally different segregation pat- terns. The NT-B procedure results in a tremendous variation in initial mtDNA distribution $(592.0 \% \pm 383.0 \%)$, although by the second stage of embryo development (G2), this variation distribution had almost completely disappeared $(92.3 \% \pm 23.5 \%)$. For the NT-F procedure, on the other hand, initial distribution was relatively uniform to the various daughter cells $(81.4 \% \pm$ $30.2 \%)$, but, in this case, by the second stage of cell development, a tremendous difference is revealed $(342.0 \% \pm 342.0 \%)$, although it had disappeared by the third (G3) stage $(44.0 \% \pm 17.4 \%)$. By the G4 stage, however, the results of the two procedures were practically the same $(135.7 \% \pm$ $17.0 \%$ vs. $94.0 \% \pm 48.3 \%$ for NT-B and NT-F, respectively). Moreover, as development progressed, an increased number in NT-B embryos with at least one blastomere showing drift to recipient cytoplasm-derived mtDNA homoplasmy (undetected $B$. indicus mtDNA) was observed as the embryo passed from one stage to the next: $1 / 14,1 / 7,2 / 9$, and $6 / 7$ for G1, G2, G3, and G4, respectively. A similar drift was observed for the

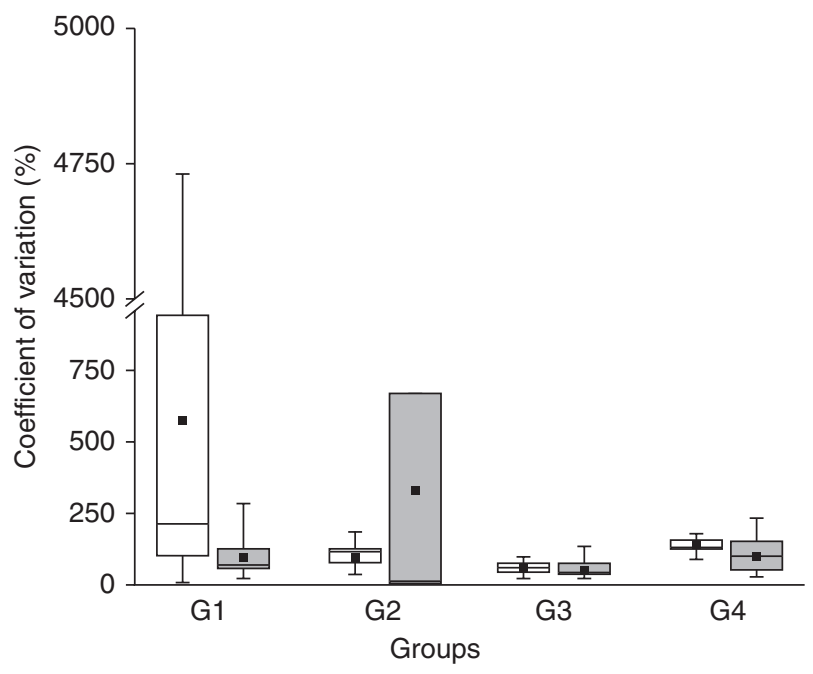

FIG. 3. Mitochondrial segregation in NT-B and NT-F embryos. Coefficient of variation ( $\mathrm{CV}$; in percentage) of heteroplasmy (vertical axis) for the five stages of embryo development for individuals arising from NT-B (without lines) and from NT-F procedures (with lines; horizontal axis). Black squares on the graph depict mean $C V$; thick bars depict median, while squares depict \pm 1 SE (upper and lower thick bars) and whiskers depict maximal and minimal CV values. Because CV cannot be calculated for two values, for those individuals at the initial stage of cell development (G1), CVs were calculated as the ratio between the value of the heteroplasmy difference between both blastomeres and that of the blastomere containing the lowest level of heteroplasmy. 
NT-F embryos. Although initial proportions were somewhat lower in this latter group, the final level was almost the same $(0 / 12,1 / 4,5 / 13$ and 5/7 for G1, G2, G3 and G4, respectively).

Despite of variation observed in the percentage of $B$. indicus mtDNA at the G4 stage, the blastocysts analysed revealed a percentage of $B$. indicus mtDNA very similar to that of the originally reconstructed zygotes in both the NT-B and NTF procedures $(11 \%$ and $13.9 \%$, for the $\mathrm{G} 1$ and $\mathrm{Blt}$ groups of the NT-B procedure vs. $4.6 \%$ and $2.2 \%$ for the G1 and Blt groups of the NT-F procedure, respectively). Because blastocysts were analyzed as a whole, it was not possible to estimate any differential distribution of donor cell-derived mtDNA within single embryos. All blastocysts in the NT-B procedure were heteroplasmic, with the exception of a single blastocyst from the NT-F procedure, all embryos had detectable levels of B. indicus mtDNA (at $1 \%$ sensitivity).

\section{Embryo transfer and cloned calf mtDNA analysis}

Embryo transfer of 7 NT-F blastocysts to five recipient cows resulted in two pregnancies, but a spontaneous abortion occurred between days 60 and 90 in one of these recipients. The other pregnancy came to term at day 290 of gestation, and the calf was delivered by Caesarean section after the induction of parturition with $30 \mathrm{mg}$ dexamethasone $36 \mathrm{~h}$ before surgery. The apparently normal female Nellore calf weighed $42 \mathrm{~kg}$, but died of septicemia and peritonitis 1 month after birth (Yamazaki et al., 2005). The white blood cells and fetal membranes collected at birth did not harbor any donor cell-derived mtDNA (Fig. 4). Moreover, an analysis of tissues, 22 primordial follicles and 6 immature oocytes collected after the death of the calf death did not reveal any $B$. indicus mtDNA (Fig. 4).

\section{DISCUSSION}

This preimplantation embryonic development experiment involved two different procedures, evaluated at five stages of development, in order to determine the proportions of donor cell mtDNA (B. indicus) present in the embryos produced by each procedure, as well as the segregation of this mtDNA during cleavage.

Previous studies in blastomere-derived cloned embryos have shown that mtDNA heteroplasmy until the blastocyst stage followed a neutral segregation pattern (Steinborn et al., 1998a) or had a consistent decrease from the eight-cell stage to the blastocyst stage of embryo development (Meirelles et al., 2001). Our results for the NT-B procedure show similar percentages for the initial and blastocyst stages, although in the stage of 9 to 16 cells, we observed a decrease in the contribution of donor blastomere-derived mtDNA.

The average heteroplasmy in the initial stage (G1) of the NT-F procedure was lower (4.7\%) than that of the NT-B procedure (11\%), due to the more limited amount of mtDNA present in the somatic cells ( $10^{3}$ to $10^{4}$ copies; Michaels, et al., 1982; Robin and Wong, 1988) than in the oocytes $(3.7 \times$ $10^{5}$ copies; May-Panloup, et al., 2005; Tamassia et

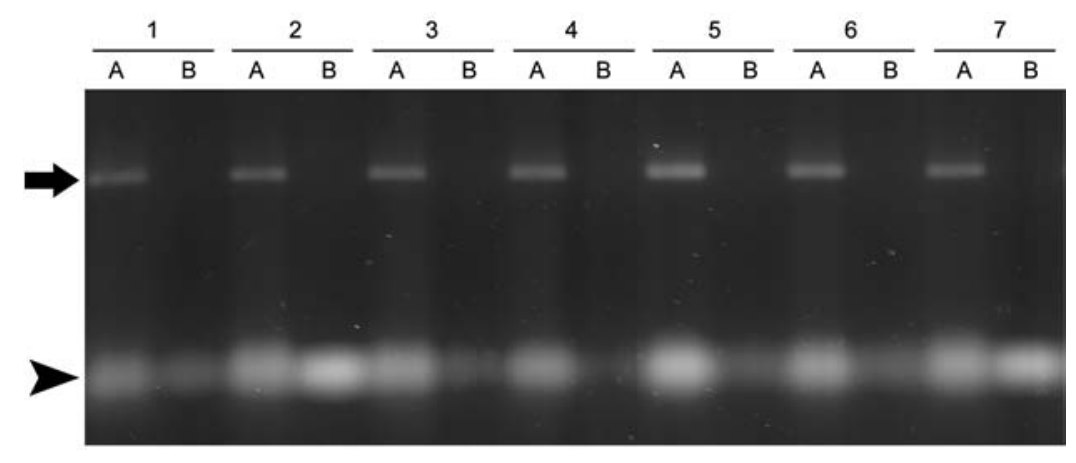

FIG. 4. Image obtained from overlaying the scanned images of one agarose gel subjected to an excitation-emission wavelength of 473-520 nm (B. taurus mtDNA) and of 532-580 nm (B. indicus mtDNA). Amplified 365-bp fragments (arrow) from oocyte (1), white blood cells (2), allantois (3), umbilical cord (4), cotyledon (5), uracus (6) and skin (7) using either B. taurus specific (A) or B. indicus specific (B) primers. Fluorochrome-stained primers remaining after the PCR are show for both wave length combinations (arrowheads). No B. indicus mtDNA was amplified in any of the tissues, suggesting an absence of donor-derived somatic cell mtDNA. 
al., 2004). However, this heteroplasmy increased gradually after the second stage of development, reaching $\sim 13 \%$ by the fourth stage $(p<0.05$; Fig. 2D).

The difference in donor cell mtDNA kinetics for the four stages of development evaluated in embryos reconstructed using the NT-B and NT$\mathrm{F}$ procedures may be explained by the distinct origins of the mitochondria. Somatic cell-derived mitochondria differ morphologically and physiologically from the embryonic organelles (Pikó and Chase, 1973). In somatic cells, the mtDNA replicates during cell cycle so that a constant number of molecules is maintained from parent to daughter cells (Birky, 1994). In bovine embryos, however, there is little information available about the factors involved in mitochondrial biogenesis and mtDNA replication until the blastocyst stage (May-Panloup et al., 2005), although differences have been reported for cloned and IVF embryos. As an example, in sheep somatic cell-derived cloned embryos, the mtTFA and polymerase $\gamma$ can be detected by immunocytochemistry until the four-cell stage, but in IVF embryos these proteins are detected only until the two-cell stage (Lloyd et al., 2006). On the other hand, studies with IVF pig embryos have shown that the level of mtTFA protein increases by the four-cell stage after embryonic genome activation, and that this is maintained at least until the blastocyst stage; moreover, increased levels of polymerase $\gamma$ protein have been observed at the outer edges of morulas (Spikings et al., 2007).

In addition to the influence of the distinct origin of mitochondria, the mitochondrial kinetics reported in the present study for NT-B and NT$\mathrm{F}$ procedures used in the reconstruction of bovine embryos may also reflect a response to the adverse conditions of IVC. In mice, there is a short period of mtDNA synthesis immediately after fertilization, which may be influenced by environment (McConnell and Petrie, 2004). Moreover, IVC has been shown to affect mitochondrial transcription and mtDNA replication (Kameyama et al., 2007). Environmental factors may thus affect embryos formed by the NT-F and the NT-B procedure differently, because somewhat different protocols for reconstruction were used. In the NT-F procedure, metaphase enucleation was performed $21 \mathrm{~h}$ post-IVM, and reconstructed embryos were partenogenetically activated at $30 \mathrm{~h}$ post-IVM using ionomycin followed by strontium. In the NT-B procedure, however, recipient oocytes were activated with ionomycin at $30 \mathrm{~h}$ post-IVM and were then enucleated after extrusion of the 2nd PB. Moreover, it's not known to what extent the further development of donor-cell mitochondria kinetics would be influenced by introduction into aged cytoplasm. Because the mitochondria used here were morphologically and physiologically distinct in the NT-B and NT-F procedures, it was not possible to estimate the effect of telophase or metaphase-enucleated recipient oocytes on the results.

Because CV values are very similar at the G3 and G4 stages for embryos produced by the two procedures, one hypothesis which might explain increased levels of donor cell heteroplasmy in the initial stages of NT-F embryo development would be that somatic mitochondria may be able to replicate during the initial phases of embryo development independent of embryonic control, because these mitochondria may have brought essential enzymes with them from the somatic cells (Gensler et al., 2001; Wiedemann et al., 2004). This replication could explain the greater quantity of mtDNA in the fourth stage (G4) of embryo development. Another possibility would be the active destruction of $\sim 60 \%$ of the embryonic mtDNA, which has been reported to occur by the eight-cell stage in the embryonic development of cattle (May-Panloup et al., 2005) and between the two-cell and the eight-cell stages of development in pigs (Spikings et al., 2007).

Despite the increased levels of somatic mtDNA at the fourth cell stage of development, this has drastically decreased by the blastocyst stage $(2.21 \%)$. This decrease may reflect the result of the large increase in replication of mtDNA occurring between the morula and the blastocyst stage, which would lead to a considerable overall increase in the amount of mtDNA present (MayPanloup et al., 2005; Smith et al., 2005; Spikings et al., 2007). Therefore, uncontrolled replication of the somatic cell-derived mtDNA and/or a wave of embryonic degradation may be involved in the proportional increase of somatic mtDNA in NT-F embryos observed at the fourth stage of development, but there is an eventual reestablishment of the original level of heteroplasmy observed. This may be related to a recognition and preferential replication of embryonic mtDNA to the detriment of that of the introduced organelles or to the degradation of somatic mitochondria (Do et al., 2001). 
In the NT-F female calf, donor cell-derived mtDNA was not detected in either white blood cells nor fetal membranes, similarly to previous reports (Meirelles, et al., 2001; Steinborn, et al., 1998b, 2000; Takeda, et al., 1999). B. taurus/B. indicus incompatibility cannot be the cause of this elimination, because, due to backcrossing origin, South American Zebu cattle (i.e., Nellore) harbor B. taurus mtDNA (Meirelles et al., 1999). Therefore, although carrying $B$. taurus mtDNA, recipient oocytes had $B$. indicus nuclear background.

Unfortunately, the death of the calf, probably reflecting the high mortality rates generally observed in cloned animals (Wells et al., 2004), did not allowed extensive study of mtDNA segregation. However, the absence of $B$. indicus mtDNA in the primordial follicles and immature oocytes, even after mtDNA amplification of the sample with $B$. indicus specific primer alone, clearly indicates the elimination of somatic mtDNA in the second generation.

These results support the hypothesis that the increased levels of somatic cell-derived mitochondria observed in the 8- to 16-cell stage of embryo development were the result of the introduction of organelles already able to replicate mtDNA, or that were able to escape the active destruction of mtDNA after embryo reconstruction. However, these organelles are less competent for replication or are preferentially degraded at the blastocyst stage. Both possibilities could be involved in the total lack of B. indicus mtDNA observed in the white blood cells, fetal membranes, and germ cells of the newborn calf.

\section{ACKNOWLEDGMENTS}

The authors are grateful to Drs. César Roberto Esper and Andréa Cristina Basso for the preantral follicles recovering; to Roberta Vantini for technical assistance in the IVF laboratory, and to Dr. Linda Gentry El-Dash for English review. This work was supported by the Foundation for the Support of Research of the State of São Paulo (FAPESP), Brazil.

\section{REFERENCES}

Andersson, U., and Scarpulla, R.C. (2001). Pgc-1-related coactivator, a novel, serum-inducible coactivator of nuclear respiratory factor 1-dependent transcription in mammalian cells. Mol. Cell. Biol. 21, 3738-3749.
Battersby, B.J.,and Shoubridge, E.A. (2001). Selection of a mtDNA sequence variant in hepatocytes of heteroplasmic mice is not due to differences in respiratory chain function or efficiency of replication. Hum. Mol. Genet. 10, 2469-2479.

Birky, C.W., Jr. (1994). Relaxed and stringent genomes: why cytoplasmic genes don't obey Mendel's laws. J. Hered. 85, 355-365.

Bordignon, V., and Smith L.C. (1998). Telophase enucleation: an improved method to prepare recipient cytoplasts for use in bovine nuclear transfer. Mol. Reprod. Dev. 49, 29-36.

Campbell, K.H. (1999). Nuclear transfer in farm animal species. Semin. Cell. Dev. Biol. 10, 245-252.

Chang, D.D., and Clayton, D.A. (1984). Precise identification of individual promoters for transcription of each strand of human mitochondrial DNA. Cell 36, 635-643.

Chen, X.J., and Butow, R.A. (2005). The organization and inheritance of the mitochondrial genome. Nat. Rev. Genet. 6, 815-825.

Clayton, D.A. (2000). Transcription and replication of mitochondrial DNA. Hum. Reprod. 15 (Suppl. 2), 11-17.

Do, J.T., Hong, K.H., Lee, B.Y., et al. (2001). In vitro development of reconstructed bovine embryos and fate of donor mitochondria following nuclear injection of $\mathrm{cu}^{-}$ mulus cells. Zygote 9, 211-218.

Evans, M.J., Gurer, C., Loike, J.D., et al. (1999). Mitochondrial DNA genotypes in nuclear transfer-derived sheep. Nat. Genet. 23, 90-93.

Gensler, S., Weber, K., Schmitt, W.E., et al. (2001). Mechanism of mammalian mitochondrial DNA replication: import of mitochondrial transcription factor A into isolated mitochondria stimulates 7S DNA synthesis. Nucleic Acids Res. 29, 3657-3663.

Giles, R.E., Blanc, H., Cann, H.M., et al. (1980). Maternal inheritance of human mitochondrial DNA. Proc. Natl. Acad. Sci. USA 77, 6715-6719.

Hiendleder, S., Schmutz, S.M., Erhardt, G., et al. (1999). Transmitochondrial differences and varying levels of heteroplasmy in nuclear transfer cloned cattle. Mol. Reprod. Dev. 54, 24-31.

Hiendleder, S., Zakhartchenko, V., Wenigerkind, H., et al. (2003). Heteroplasmy in bovine fetuses produced by intra- and inter-subspecific somatic cell nuclear transfer: Neutral segregation of nuclear donor mitochondrial DNA in various tissues and evidence for recipient cav mitochondria in fetal blood. Biol. Reprod. 68, 159-166.

Hutchinson, C.A., 3rd, Newbold, J.E., Potter, S.S., et al. (1974). Maternal inheritance of mammalian mitochondrial DNA. Nature 251, 536-538.

Jenuth, J.P., Peterson, A.C., Fu, K., et al. (1996). Random genetic drift in the female germ line explains the rapid segregation of mammalian mitochondrial DNA. Nat. Genet. 14, 146-151.

Kameyama, Y., Filion, F, Yoo, J.G., et al. (2007) Characterization of mitochondrial replication and transcription control during rat early development in vivo and in vitro. Reproduction 133, 1-11.

Lloyd, R.E., Lee, J.H., Alberio, R., et al. (2006). Aberrant nucleo-cytoplasmic cross-talk results in donor cell 
mtDNA persistence in cloned embryos. Genetics 172, 2515-2527.

Loftus, R.T., MacHugh, D.E., Bradley, D.G., et al. (1994). Evidence for two independent domestications of cattle. Proc. Natl. Acad. Sci. USA 91, 2757-2761.

MacHugh, D.E., Shriver, M.D., Loftus, R.T., et al. (1997). Microsatellite DNA variation and the evolution, domestication and phylogeography of taurine and zebu cattle (Bos taurus and Bos indicus). Genetics 146, 1071-1086.

May-Panloup, P., Vignon, X., Chrétien, M.F., et al. (2005). Increase of mitochondrial DNA content and transcripts in early bovine embryogenesis associated with upregulation of mtTFA and NRF I transcription factors. Reprod. Biol. Endocrinol. 3, 65.

McConnell, J.M.L., and Petrie, L. (2004). Mitochondrial DNA turnover occurs during preimplantation development and can be modulated by environmental factors. RBM Online 9, 418-424.

Meirelles, F.V., and Smith, L.C. (1997). Mitochondrial genotype segregation in a mouse heteroplasmic lineage produced by embryonic karyoplast transplantation. Genetics 145, 445-451.

Meirelles, F.V., and Smith, L.C. (1998). Mitochondrial genotype segregation during preimplantation development in mouse heteroplasmic embryos. Genetics 148, 877-883.

Meirelles, F.V., Rosa, A.J.M., Lôbo, R.B., et al. (1999). Is the American zebu really Bos indicus? Genet. Mol. Biol. 22, 543-546.

Meirelles, F.V., Bordignon, V., Watanabe, Y., et al. (2001). Complete replacement of the mitochondrial genotype in a Bos indicus calf reconstructed by nuclear transfer to a Bos taurus oocyte. Genetics 158, 351-356.

Michaels, G.S., Hauswirth, W.W., and Laipis, P.J. (1982). Mitochondrial DNA copy number in bovine oocytes and somatic cells. Dev. Biol. 94, 246-251.

Pieterse, M.C., Kappen, K.A., Kruip, Th. A.M., et al. (1988). Aspiration of bovine oocytes using transvaginal ultrasound scanning of the ovaries. Theriogenology 30, 751-762.

Pikó, L., and Chase, D.G. (1973). Role of the mitochondrial genome during early development in mice. Effects of ethidium bromide and chloramphenicol. J. Cell Biol. 58, 357-378.

Plante, Y., Schmutz, S.M., and Lang, K.D.M. (1992). Restriction length polymorphism in the mitochondrial DNA of cloned cattle. Theriogenology 38, 897-904.

Puigserver, P., Wu, Z., Park, C.W., et al. (1998). A coldinducible coactivator of nuclear receptors linked to adaptive thermogenesis. Cell 92, 829-839.

Robin, E.D., and Wong, R. (1988). Mitochondrial DNA molecules and virtual number of mitochondria per cell in mammalian cells. J. Cell Physiol. 136, 507-513.

Sambrook, J., and Russel, D.W. (2001). Molecular cloning: a laboratory manual. In Rapid Isolation of Mammalian DNA. 3rd ed. (New York: Cold Spring Harbor Laboratory Press) pp. 6.28-6.30.

Scarpulla, R.C. (1997). Nuclear control of respiratory chain expression in mammalian cells.J. Bioenerg. Biomembr. 29, 109-119.
Schutz, M.M., Freeman, A.E., Lindberg, G.L., et al. (1994). The effect of mitochondrial DNA on milk production and health of dairy cattle. Livestock Prod. Sci. 37, 283-295.

Smith, L.C., and Alcivar, A.A. (1993). Cytoplasmic inheritance and its effects on development and performance. J. Reprod. Fertil. Suppl. 48, 31-43.

Smith, L.C., Thundathil, J., and Filion, F. (2005). Role of the mitochondrial genome in preimplantation development and assisted reproductive technologies. Reprod. Fertil. Dev. 17, 15-22.

Spikings, E.C., Alderson, J., and St. John, J.C. (2007). Regulated mtDNA replication during oocyte maturation is essential for successful porcine embryonic development. Biol. Reprod. 76, 327-335,

Steinborn, R., Zakhartchenko, V., Jelyazkov, J., et al. (1998a). Composition of parental mitochondrial DNA in cloned bovine embryos. FEBS Lett. 426, 352-356.

Steinborn, R., Zakhartchenko, V., Wolf, E., et al. (1998b). Non-balanced mix of mitochondrial DNA in cloned cattle produced by cytoplast-blastomere fusion. FEBS Lett. 426, 357-361.

Steinborn, R., Schinogl, P., Zakhartchenko, V., et al. (2000). Mitochondrial DNA heteroplasmy in cloned cattle produced by fetal and adult cell cloning. Nat. Genet. 25, 255-257.

Steinborn, R., Schnogl, P., Wells, D.N., et al. (2002). Coexistence of Bos taurus and B. indicus mitochondrial DNA in nuclear transfer-derived somatic cattle clones. Genetics 162, 823-829.

Sutovsky, P., Moreno, R.D., Ramalho-Santos, J., et al. (1999). Ubiquitin tag for sperm mitochondria. Nature 402, 371-372.

Takeda, K., Takahashi, S., Onishi, A., et al. (1999). Dominant distribution of mitochondrial DNA from recipient oocytes in bovine embryos and offspring after nuclear transfer. J. Reprod. Fertil. 116, 253-259.

Takeda, K., Takahashi, S., Onishi, A., et al. (2000). Replicative advantage and tissue-specific segregation of RR mitochondrial DNA between C57BL/6 and RR heteroplasmic mice. Genetics 155, 777-783.

Tamassia, M., Nuttinck, F., May-Panloup, P., et al. (2004). In vitro embryo production efficiency in cattle and its association with oocyte adenosine triphosphate content, quantity of mitochondrial DNA, and mitochondrial DNA haplogroup. Biol. Reprod. 71, 697-704.

Vajta, G., Rindom, N., Peura, T.T., et al. (1999). The effect of media, serum and temperature on in vitro survival of bovine blastocysts after Open Pulled Straw (OPS) vitrification. Theriogenology 52, 939-948.

Wells, D.N., Misica, P.M., and Tervit, H.R. (1999). Production of cloned calves following nuclear transfer with cultured adult mural granulosa cells. Biol. Reprod. 60, 996-1005.

Wells, D.N., Forsyth, J.T., McMillan, V., et al. (2004). The health of somatic cell cloned cattle and their offspring. Cloning Stem Cells 6, 101-110. 
Wiedemann, N., Frazier, A.E., and Pfanner, N. (2004). The protein import machinery of mitochondria. J. Biol. Chem. 279, 14473-14476.

Williams, R.S. (1986). Mitochondrial gene expression in mammalian striated muscle. Evidence that variation in gene dosage is the major regulatory event. J. Biol. Chem. 261, 12390-12394.

Yamazaki, W., Ferreira, C.R., Méo, S.C., et al. (2005). Use of strontium in the activation of bovine oocytes reconstructed by somatic cell nuclear transfer. Zygote 13, 295-302.
Address reprint requests to: Christina Ramires Ferreira Medicina Veterinária Preventiva e Reprodução Animal Universidade de São Paulo-UNESP Via de Acesso Prof. Paulo Donato Castellane $s / n$ Jaboticabal, Brazil

E-mail: christina.ferreira@posgrad.fcav.unesp.br 